\title{
Realizing the Need for Digital Transformation of Stakeholder Management: A Systematic Review in the Construction Industry
}

\author{
Kristijan Robert Prebanić* *D and Mladen Vukomanović
}

check for

updates

Citation: Prebanić, K.R.; Vukomanović, M. Realizing the Need for Digital Transformation of Stakeholder Management: A Systematic Review in the Construction Industry. Sustainability 2021, 13, 12690. https://doi.org/ $10.3390 /$ su132212690

Academic Editors:

Mladen Vukomanovic and

Michał Juszczyk

Received: 30 September 2021

Accepted: 9 November 2021

Published: 16 November 2021

Publisher's Note: MDPI stays neutral with regard to jurisdictional claims in published maps and institutional affiliations.

Copyright: (c) 2021 by the authors. Licensee MDPI, Basel, Switzerland. This article is an open access article distributed under the terms and conditions of the Creative Commons Attribution (CC BY) license (https:// creativecommons.org/licenses/by/ $4.0 /)$.
Department for Organization, Technology and Management, Faculty of Civil Engineering, University of Zagreb, 10000 Zagreb, Croatia; mvukoman@grad.hr

* Correspondence: kprebanic@grad.hr

\begin{abstract}
The construction industry is among the least digitized industries, and the lack of innovation in construction project management practices has led to decreases in productivity. The European Directives for Public Procurement are pushing the entire construction supply chain towards more radical digital transformations over the next years, and project managers are left with the difficult task to harness ICT for the involvement and management of project stakeholders. Digitalization of various processes and practices used to manage stakeholders in construction projects is still low, and part of this problem lies in weak systematization of ICT systems which support these practices. Thus, this paper provides a systematic review of how digitalization and digital transformation affect the way stakeholders behave, engage, and communicate in projects. Following the PRISMA methodology, 73 sources from the literature were chosen for the final analysis. Results are presented through descriptive and qualitative content analysis. Six research topics were identified and thoroughly analyzed. Results show that BIM, social network analysis, and web-based applications as means to digitalize stakeholder management are more mature than social media and VR/AR. An important finding is the need to reengineer and digitally transform processes in construction projects and construction firms to enable further digitalization and effectiveness of digital technologies. Suggestions for further studies follow this line of thought.
\end{abstract}

Keywords: digitalization; digital transformation; stakeholder management; construction industry; systematic review

\section{Introduction}

\subsection{Importance of Digitalization in the Construction Industry}

The construction industry is characterized by highly interdisciplinary, fragmented, and temporary project organizations, process discontinuities, and unique projects [1], and this fragmentation is making it very difficult to meet construction project requirements in terms of cost, time, and productivity [2]. Complexity is added by the reciprocal interdependencies between different stakeholders, such as financing bodies, authorities, architects, engineers, and many others, which makes it necessary for construction projects to improve integration, cooperation, communication, and coordination [3]. Important elements of stakeholder interaction are information management and communication processes, which are considered to be main constituents of efficient human cooperation [4]. Documents serve as a key information carrier, and in today's business world, they are mainly handled as individual computer files, which requires ICT for their creation and storage [5]. The construction project aspects mentioned illuminate the fact that they are very dependent on reliable and updated information and thus require a number of ICT-based business systems, communication tools, and shared storage servers [6].

The construction sector has been slow to adopt innovations in processes and organization, and in general, it has not yet embraced new digital technologies, which is corroborated 
by the fact that the construction industry is among the least digitized industries [7]. The lack of innovation in construction project management practices has been described as having led to lost productivity [2]. Additionally, there is a growing demand for making the construction industry more sustainable, which also requires changes in traditional practices [7]. The McKinsey Global Institute estimates that the world will need to spend USD 57 trillion on infrastructure by 2030, which is a massive opportunity for the digital transformation of the construction industry [7]. Digitalization is a hot topic in the construction industry today, which is corroborated by a great number of developed ICT tools [8]. Web-based project platforms, digital meetings, and BIM have all existed for quite a while [8], although they are mostly not used to their full potential [1]. It Is apparent that ICT is essential in daily work for most professionals in the construction industry [9], and Jahanger et al. [2] showed that proper digitalization of construction and project management practices can help in reversing the decline in productivity. The European Directives for Public Procurement are pushing the entire construction supply chain towards more radical transformations over the next years by supporting research, development, and training for digitalization [10].

\subsection{Digitalizing Construction Stakeholder Management Practices to Enhance Performance in Construction Projects}

Large construction projects are mostly focused on overcoming current infrastructure capacity problems or opening new business opportunities [11], and they bear great importance for the promotion of the economic and social wellbeing of the wider stakeholder community. These projects include numerous contracting parties and a vast range of potentially conflicting interests, which requires highly complex problem-solving activities such as stakeholder management [12]. Stakeholder management comprises two major processes (e.g., stakeholder analysis and engagement) [13], and it is increasingly becoming a part of construction project practice [14]. Inadequate stakeholder management has led to process disruptions and adverse outcomes in many large construction projects [11,12] and it is considered as a fundamental instrument for setting the direction of projects [15]. Additionally, there is a great need to manage stakeholders through various engagement strategies (i.e., communication, partnership, and capacity building strategy) to increase the sustainability of construction projects [16]. Significant empirical research conducted in recent years further divides stakeholder analysis processes (i.e., stakeholder identification, classification, assessment of stakeholder influence, etc.) [17-20] and stakeholder engagement processes (i.e., stakeholder communication, involvement, collaboration, etc.) $[13,21,22]$ which is consistent with stakeholder management becoming a formal project management knowledge area [23]. The project management body of knowledge (PMBOK) standard [24] for project management formalizes stakeholder management through four processes (identification of project stakeholders, planning of stakeholder engagement, management of stakeholder engagement and monitoring, and control of stakeholder engagement), which comprise several underlying practices.

Through rapid advancements in ICT, opportunities arise in enhancing communication between participants of different organizations (i.e., internal stakeholders) in construction projects [24]. Furthermore, obtaining external stakeholder support necessitates strategic engagement, often using information and communications technology (ICT) [25]. Building information modelling (BIM) promotes the collaborative working of different stakeholders, enabling them to support and reflect their respective responsibilities by inserting, extracting, updating, and sharing information through the BIM model [26]. Computer-mediated collaboration has been the main focus of Computer Supported Collaborative Working (CSCW) studies, which deal with ICT-supported information sharing, information exchange, collaborative decision making, and control protocols [27]. Web (cloud) applications exploit Internet and web technologies to enhance information sharing between various project stakeholders throughout the project lifecycle [28]. In large construction projects, ICT supported visualization and simulation are considered very important for coordination of both internal and external stakeholders [29]. Additionally, software packages supporting a social network analysis method (i.e., UCINET, NetMiner, etc.) can be used to analyze and 
visualize stakeholder relationship networks and their influence. Ninan et al. [25] provides evidence that ICT was used strategically to hegemonize stakeholder support and persuade stakeholders to support project decisions. They emphasized social media as a key type of ICT system which can assist in conducting stakeholder engagement strategies.

Using digital technology for communication and collaboration is often seen as an important managerial tool, and project managers are left with the increasingly important task of finding proper ways to harness ICT collaboration tools for the involvement of project stakeholders $[30,31]$ The digitalization of various construction project management practices is relatively well researched, considering the number of various ICT tools and articles dealing directly or indirectly with this broad research field. Nevertheless, the adoption of the digital way of performing project and stakeholder management practices in construction projects is still very low compared to some other industries [25], and part of this problem lies in the weak systematization of ICT systems which support these practices. There is not enough information on what a particular ICT tool serves for, which stakeholder should use it, and for what purposes; in other words, research streams related to the digitalization of various management processes and activities (i.e., stakeholder engagement, collaboration, analysis, etc.) are vague. There are numerous papers dealing with the collaboration and cooperation of specific internal construction project stakeholders through various ICT tools (i.e., contractor with subcontractors, project manager with other stakeholders), and on the other hand, ICT usage for external stakeholder involvement and analysis (i.e., project end users) is becoming an increasingly important topic. Therefore, this study analyzes a body of literature and answers the following questions:

- "What are the general ways of using ICT systems and tools to manage construction project stakeholders?"

- "Which processes and underlying practices of construction stakeholder management are digitalized and to what extent?"

- "What are the circumstances in which digital stakeholder management is needed in future research?"

In other words, the main goals of this paper are to provide a systematic review of how digitalization and digital transformation affects the way stakeholders behave, engage, and communicate in construction projects.

In this introductory section, the research field encompassing the digital approach to project stakeholder management is presented, followed by a stipulation of the main research goals. Section 2 presents the systematic literature review methodology chosen to achieve the research goals, and the results are presented in Section 3. The results are organized through descriptive and qualitative analysis presented in two main subsections. The qualitative analysis provides six research topics, each presented in separate subsection. Discussion and further suggestions are provided in Section 4 for the research topics identified in the results. The last section presents the conclusion, in which the importance of digital transformation is highlighted.

\section{Sources and Methods}

\subsection{Systematic Literature Review}

Researchers use systematic literature reviews (SLR) to provide readers with syntheses and analyses of research in specific subject areas, as well as to establish a framework for future research [32]. The approach is particularly suitable when the analyzed subject is fragmented across fields of study [33], which has previously been portrayed for the area of digitalized stakeholder management practices. In this study, a selection and analysis of papers is conducted following the established PRISMA statement methodology [34], where PRISMA stands for "preferred reporting items for systematic reviews and meta-analyses". The PRISMA statement is a checklist covering all critical issues that should be reported and consists of a flow diagram that presents the research procedure. The paper adopts the PRISMA statement to avoid errors and bias and provide high-quality results. For qualitative and quantitative content analysis of the chosen papers, we used the guidelines 
provided by Seuring and Gold [35] on how to properly conduct and report a content analysis type of literature review. For content analysis purposes, we iteratively developed precise codes related to our research topic [35] and presented them in a table codebook (Table 1) [36].

Table 1. Codebook for content analysis of this study. Adapted from Laplume et al. [36].

\begin{tabular}{|c|c|}
\hline Code & Definition of Code \\
\hline \multicolumn{2}{|l|}{ Quantitative variables coded } \\
\hline Authors & List of authors \\
\hline Article title & Title of the article \\
\hline Source title (journal) & Publication in which the article was published \\
\hline Publication year & Year of publication \\
\hline Research methodology & $\begin{array}{l}\text { Case study, conceptual research, survey, mixed-methods, app } \\
\text { development, literature review, other }\end{array}$ \\
\hline Stakeholder category & Two major stakeholder categories (internal or external or both) \\
\hline Stakeholder management process & Two major stakeholder processes (analysis or engagement or both) \\
\hline ICT/digital technology, tool, or system & $\begin{array}{c}\text { Web, web-based application, BIM 3D, BIM 4D/5D, social media, VR/AR, } \\
\text { social network analysis, etc. }\end{array}$ \\
\hline Project phase & $\begin{array}{l}\text { Three project phases (conceptualization, design, construction) or } \\
\text { combination or non-applicable }\end{array}$ \\
\hline \multicolumn{2}{|l|}{ Qualitative variables coded } \\
\hline Link between digital and stakeholder management & $\begin{array}{c}\text { Link between ICT system and stakeholder management process/practice } \\
\text { explicitly stated in the article }\end{array}$ \\
\hline Contributions & $\begin{array}{c}\text { Contributions explicitly stated in the article (regarding ICT supported } \\
\text { stakeholder management) }\end{array}$ \\
\hline Major findings & $\begin{array}{c}\text { Major findings explicitly stated in the article (regarding ICT supported } \\
\text { stakeholder management) }\end{array}$ \\
\hline
\end{tabular}

\subsection{Research Procedure}

The SLR approach is consistent with suggestions made by [33,35]. It is compatible with the PRISMA method and includes the following steps:

- Identification of initial studies;

- Title, abstract, and keywords screening;

- Full-text screening;

- Qualitative and quantitative analysis of included papers;

- Detecting possible future research streams;

- Stating the research limitations;

- Presentation of summarized results and new insights.

We followed a PRISMA procedure which contains four main stages (Figure 1) and provides clear method for the retrieval of a final set of papers, which are then analyzed. 


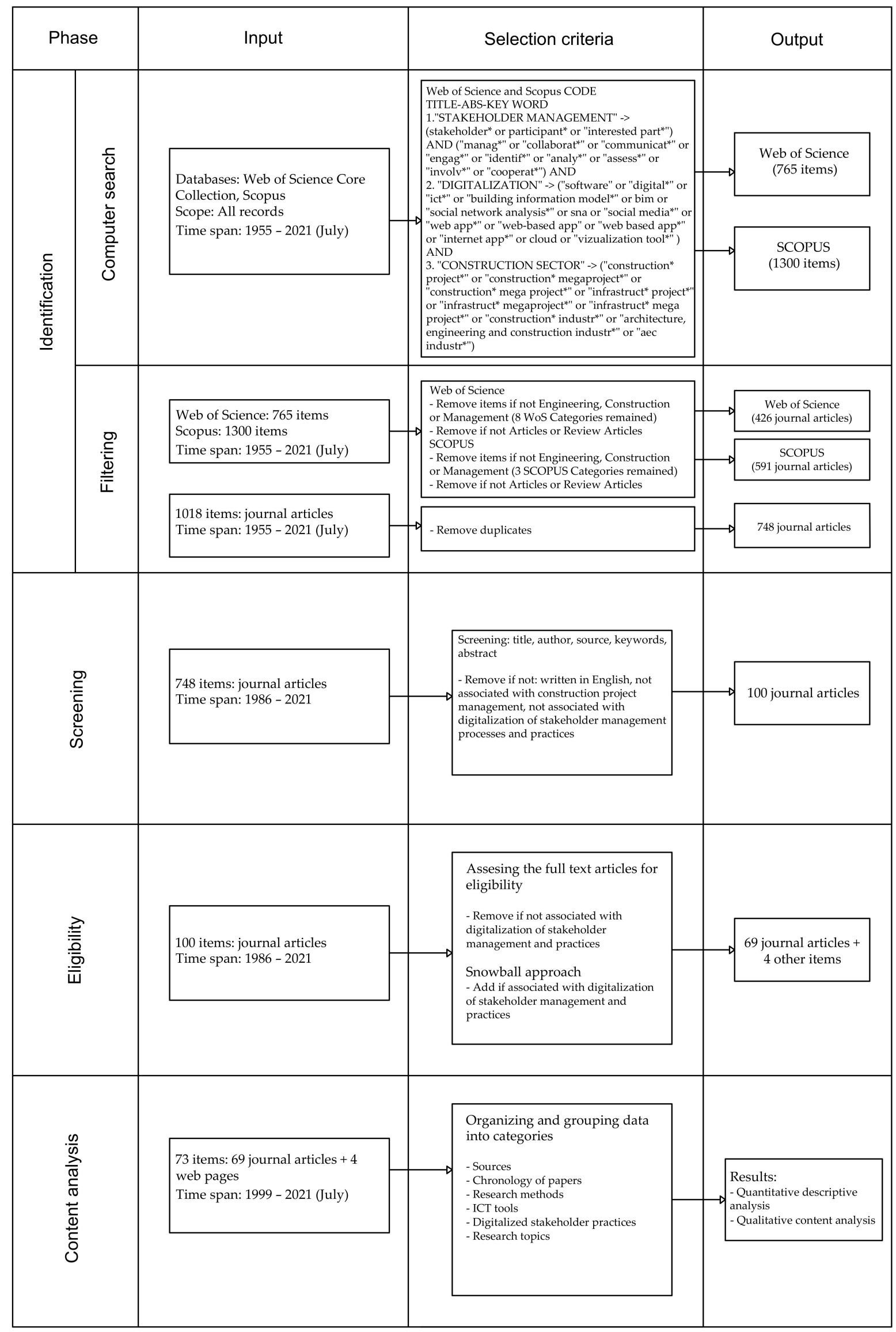

Figure 1. Research methodology. 
In stage 1 (identification), we conducted a comprehensive exploratory desktop literature search through two major databases of scientific literature, namely "Web of Science Core Collection" and "Scopus". These databases are the largest citation and abstract databases of peer-reviewed literature that deliver an overview of the world's research output in the fields of technology, science, etc. [37]. This stage was done through sub-stages of computer search and filtering. Computer search was done through keywords for "digital" and "stakeholder management", which was searched in context of "construction projects". Each keyword was supplemented with various expressions used as a proxy, i.e., "construction* project*" was supplemented with "AEC industry*", "construction industry", "infrastructure mega-project", etc. Stakeholder management has been categorized and classified into the several processes and practices of stakeholder analysis and stakeholder engagement presented in the previous section, so we used them as a proxy for the stakeholder management discipline. Furthermore, we divided "stakeholder" and "management" (and their proxies) in order to prevent excluding valuable sources because expressions are often stated in various ways, i.e., "managing project stakeholders". For "digitalization" we also used various proxy terms, i.e., keywords such as "BIM", "ICT", "cloud", "social network analysis", etc. These proxy terms either carry the same meaning as "digital*" or are associated with ICT tools and systems, which are very commonly used for practices of stakeholder analysis and engagement. An initial search retrieved 2065 items. Filtering was done using WoS and SCOPUS filters to exclude items that were not remotely related to the broad fields of engineering and management and those which were not journal articles. Finally, we removed duplicates and finished this stage with 748 journal articles compared to the 2065 items which were retrieved in the initial database searches.

In stage 2, screening was performed on 748 journal articles that were screened by their title, abstract, source, and keyword list. We screened out journal articles which were not written in English, were not associated with the digitalization of stakeholder management processes (i.e., articles dealing with a "BIM-Based Research Framework for Sustainable Building ..." "), and did not fall into the construction project management context (i.e., articles dealing with the "Industrial Revolution 4.0 in the construction industry ... "). This resulted in the exclusion of 648 journals articles, so 100 remained for stage 3.

In stage 3, the goal was to check papers for eligibility and retrieve a final set of items which would undergo quantitative and qualitative analysis. Journal articles were visually examined, and each article that did not provide any valuable conclusion on a digitalized approach to various stakeholder analysis or engagement practices (i.e., articles dealing with "Relationally integrated value networks (RIVANS) for total facilities ... ") or, in other words, that did not explicitly link stakeholder management practices with any form of ICT was excluded. Furthermore, in this stage, we performed a snowball approach by analyzing the literature references in the examined articles, and we also performed a brief Google search to assure that every relevant source was included. Through our search, we found two additional ICT systems for construction stakeholder management and retrieved a few more sources and added them to our final set.

Finally, in stage 4 , the contents of 69 eligible articles and 4 other sources were considered for a content analysis. For this study, content analysis was appropriate because it could be used to determine the major facets of a set of data by counting the number of articles that elaborate a specific process, ICT tool, or topic [38]. Additionally, both qualitative and quantitative analysis methods were employed in this study. We focused our qualitative content analysis on the identification of research topics and findings (specifically the connection between an ICT tool or system and stakeholder management process); the project phases studied (three major phases of conceptualization, design, and construction); the main research methods used in the article; publication chronology; and source attributes (research journal and author/s). On the other hand, a quantitative content analysis was conducted to statistically categorize the identified contents in each article. 


\subsection{Content Analysis of Retrieved Articles}

For the content analysis-based literature review, we followed guides that are provided by Seuring and Gold [35]. The coding rules (Table 1) offered a highly reliable method for the quantitative and qualitative analysis of the papers. We followed a two-step process approach elaborated in [35] of developing a pattern of analytic categories: after the basic frame of categories and dimensions (e.g., codes) has been established on the basis of existing theory, single categories are inductively refined during the coding process. Initial coding rules were developed iteratively, as were six research topics which were identified based on codes. In addition to usual codes for scientific articles (i.e., journal name, authors, title, publication year), we also added our own to enrich the overall descriptive and qualitative content analysis (Table 1). Two coders iteratively conducted the content analysis on the full manuscripts of the selected articles, which ensured the reliability of the analysis [35]. In descriptive analysis, we analyzed 69 journal articles for each point of analysis (e.g., each code), and in the qualitative content analysis, we added the other four sources (webpages), which means that 73 sources were qualitatively analyzed.

\section{Results}

In this section, we present the results of the content analysis, which was divided into two streams. First, we present the descriptive analysis which was done through various points of analysis (codes in Table 1), and the second section presents the results of the qualitative analysis. Descriptive analysis provides general information about research journals, years of publication, and research methodology applied in each article. Furthermore, we investigated the phases of the construction project that were analyzed in the articles, and we concluded descriptive analysis with identification of ICT systems and the stakeholder management processes for which they were used. The descriptive analysis provided sufficient insight to recognize the specific topics in stakeholder management digitalization. These topics are subject of further examination, which is done through content analysis in the second subsection of this section. Content analysis provides detailed and broad insight in the digitalized construction stakeholder management research field, where points of analysis are digitalized stakeholder management practices which provide transformation and improvements in stakeholder analysis and engagement.

\subsection{Descriptive Analysis}

In the methodology section, it can be seen that 69 sources were journal articles, and there are an additional four other sources (e.g., websites). Descriptive analysis is made for all journal articles, which were analyzed through structured coding (Table 1), and four websites which do not fall into the coding scheme were added in the qualitative content analysis.

In Table 2, the distribution of selected publications in different journals is represented. These journals covered the research area of the digitalized approach to various stakeholder management practices. The papers included in this study were published in 37 journals. There is no single prevailing journal for the observed research area, but two journals encompassing the field of ICT in construction (project) management are logically the most popular on this subject. Automation in Construction and the Journal of Information Technology in Construction each published seven articles on this topic, followed by the International Journal of Project Management with six and the Journal of Construction Engineering and Management with four articles. These four journals published more than one third of all articles dealing with the digitalization of stakeholder management practices, and more than half of the articles are published in the first eight journals (Table 2). 
Table 2. Distribution of selected journal articles.

\begin{tabular}{cc} 
Journal Title & Number of Articles \\
\hline Automation in Construction & 7 \\
Journal of Information Technology in Construction & 7 \\
International Journal of Project Management & 6 \\
Journal of Construction Engineering and Management & 4 \\
Construction Innovation & 3 \\
Construction Management and Economics & 3 \\
Facilities & 3 \\
Project Management Journal & 3 \\
Architectural Engineering and Design Management & 2 \\
Engineering, Construction and Architectural Management & 2 \\
Journal of Management in Engineering & 2 \\
Transportation Research Record & 2 \\
Other & 25 \\
\hline
\end{tabular}

Based on the year-wise distribution of the selected articles (Figure 2), we identified three specific periods: the first period was before 1999, when this subject was not explored; the second was a 16-year period from 1999 to 2015, when 19 scientific journal articles were published, which is slightly more than one article per year; and the last was the 6.5 year period from 2015 to 2021, when this research field is being researched at an accelerated pace. As many as 50 scientific journal articles were published in the last 6.5 years, which emphasizes the importance of the area dealing with digital construction stakeholder management.

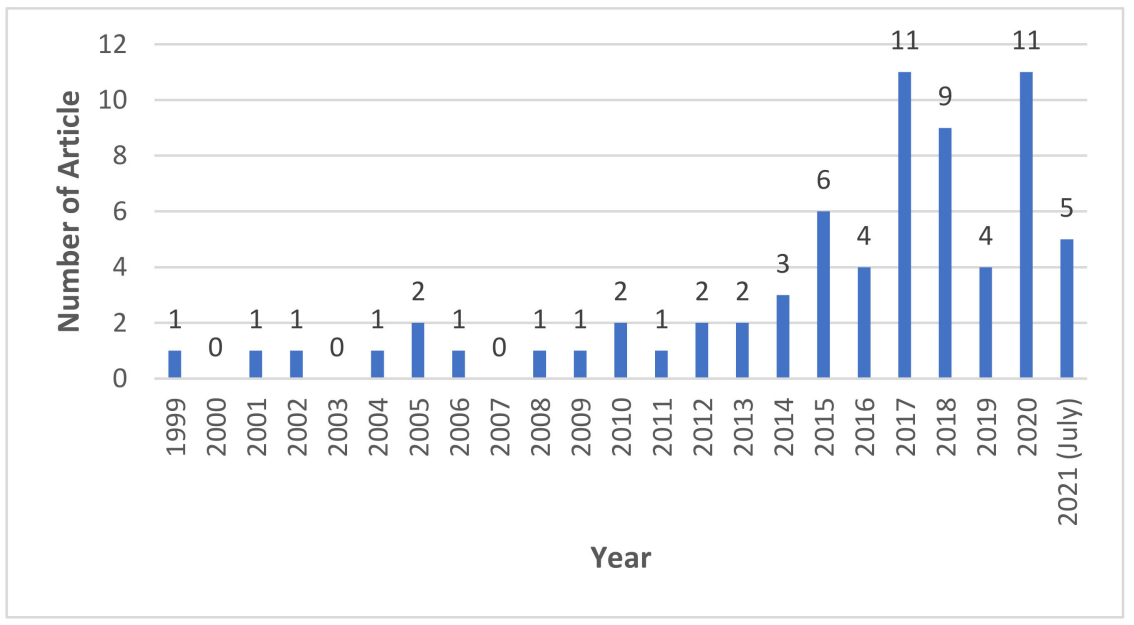

Figure 2. Year-wise distribution of the selected papers.

We classified the research methodologies into six categories which are based on the dominant research method used in article (e.g., mixed methods articles consisted of a few equally addressed research methods).

The seventh category to which we refer as "other research methodology" comprises seven articles, each having a specific research methodology which does not fall into any stipulated category (Figure 3). Almost half of the selected articles are based on the case study methodology, which comprises various means of data collection and analysis, followed by mixed methods, conceptual frameworks, surveys, and articles that elaborate the process of software application development. Additionally, two review articles came up in the selected papers, and seven articles had a specific methodology that did not appear in any other article. 


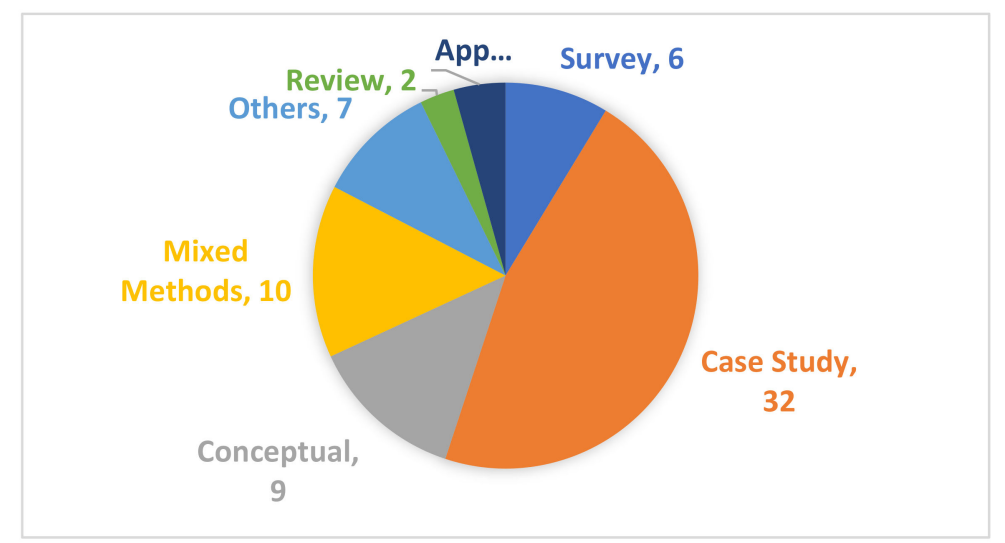

Figure 3. Distribution of articles' research methodology.

A large portion of the selected articles addressed the specific project phase on which they conducted their research. This encouraged us to examine each article and determine which project phase was in focus. First, we determined three project phases, namely the conceptualization, design, and construction phases. The articles either observe one or multiple project phases and thus fall into one of the categories shown in Figure 4. Furthermore, there are articles in which the authors reported observations regarding previously completed projects which they chose for a case study. These observations referred to a particular project phase, or the ICT usage described in the project was applied throughout the whole project lifecycle (e.g., all phases). Thus, we added a category encompassing all project phases. In nine articles, the authors either elaborated the basic principles of digital stakeholder management practices, or they conducted a survey in which it was not possible to claim with certainty which phase was addressed (i.e., opinions of practitioners were surveyed), so they were labeled as non-applicable (N/A). We coupled the project phase with the construction stakeholder management process which was addressed in the article, and this is shown in Figure 4.

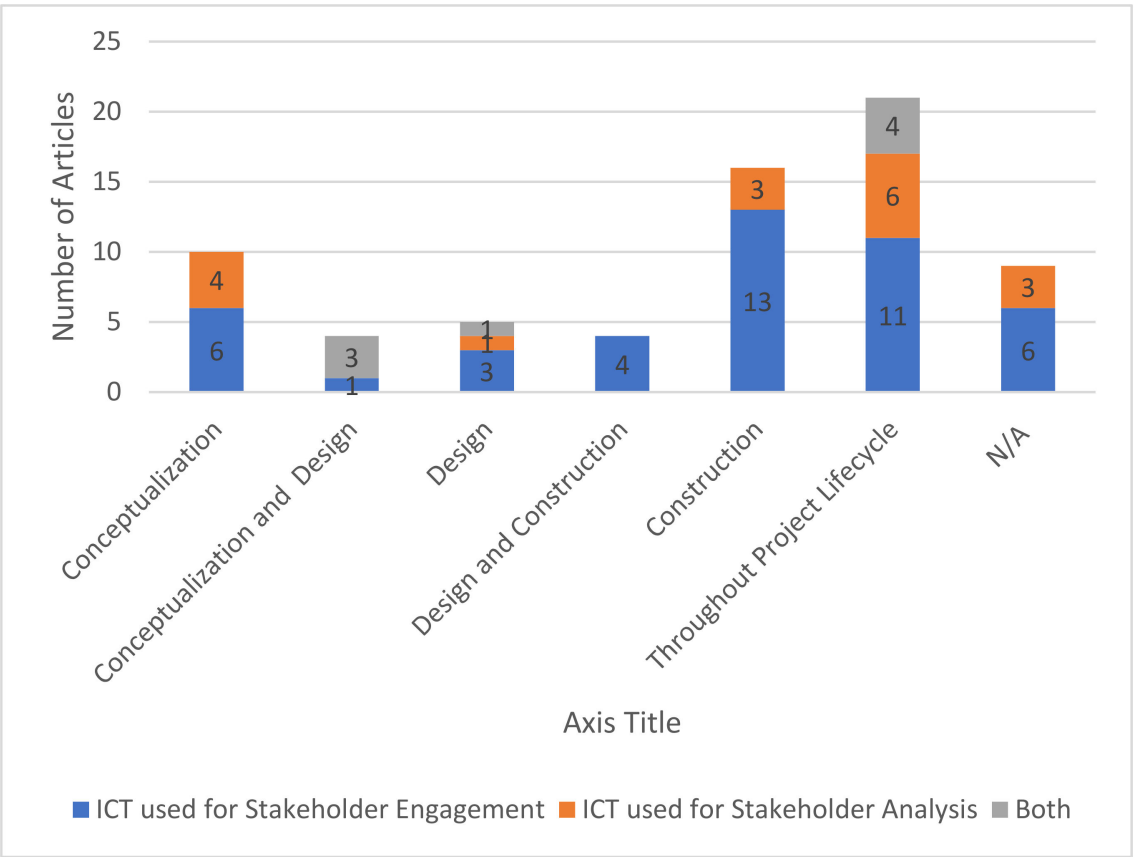

Figure 4. Distribution of project phases and addressed stakeholder management process.

The most relevant codes we used in the analysis were the code referring to the ICT technology or system described in the article and the code referring to one of two 
major stakeholder management processes that was applied in digital form. Additionally, interesting information on this subject consists of knowing which types of stakeholders were addressed, so we used the classification provided by Winch [39], which categorizes stakeholders into two major groups of internal stakeholders (i.e., contracted parties such as the contractor) and external stakeholders (i.e., indirectly involved such as the affected local community). As this paper's main goal is to systematically examine the literature dealing with the digitalization of construction stakeholder management practices, we organized the information in Table 3 to portray which ICT systems are used by particular stakeholder groups and more importantly for which stakeholder management processes. We also added a year-wise distribution of these articles in Table 3, which is linked to stakeholder management processes, to present the results more accurately. To explain the social network analysis approach to stakeholder analysis in more detail, we divided the stakeholder analysis process into the pre-engagement analysis done as a part of project planning and the post-engagement analysis done for the purpose of the evaluation of the actions and influences of stakeholders. The information organized in this manner helped us in detecting the specific topics in construction stakeholder management digitalization, which will be further elaborated in qualitative content analysis. 
Table 3. Selected articles organized by addressed ICT systems, type of stakeholder group, and stakeholder management processes, followed by their period of publication.

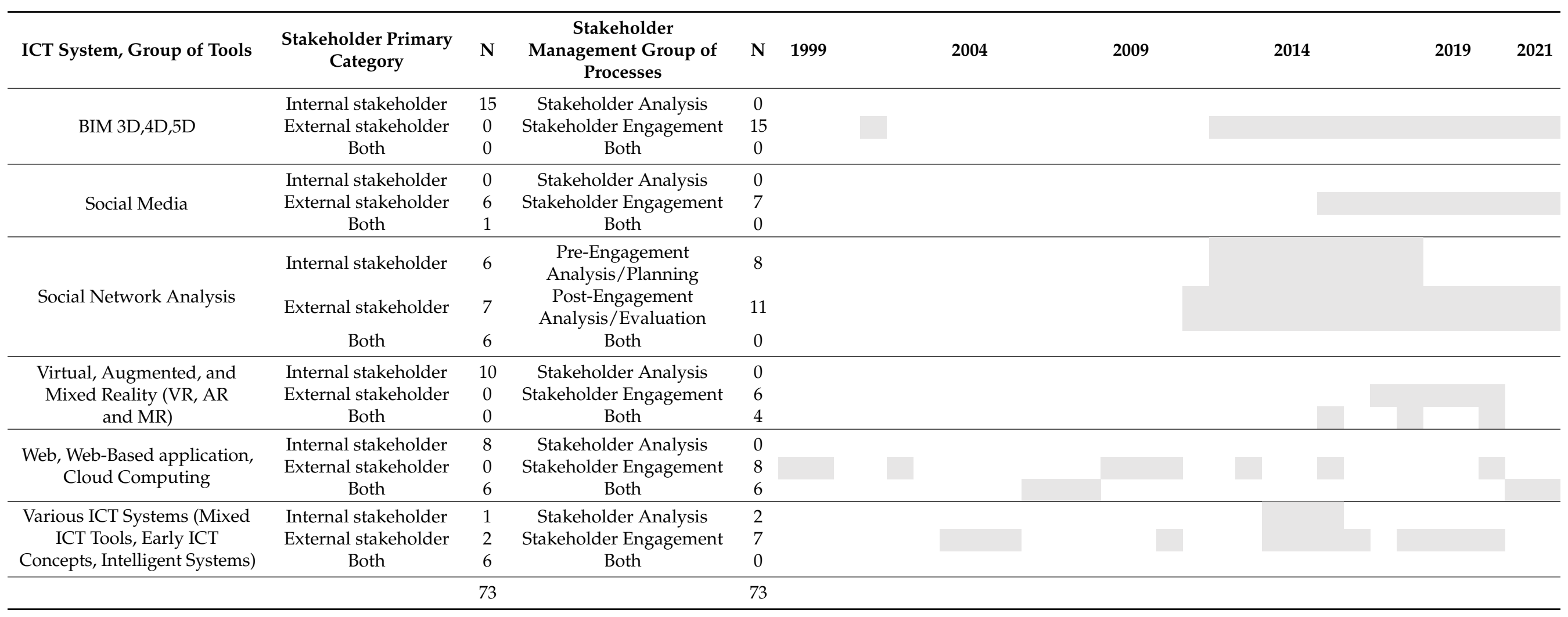




\subsection{Content Analysis-Construction Stakeholder Management Digitalization}

The results of the qualitative content analysis were presented through six main topics that connect digital (ICT) technology (tool or system) with various types of stakeholder management processes and practices. Topics were developed iteratively by a thorough analysis of ICT systems used to digitalize stakeholder management practices, and some articles covered a very broad research field. The first topic presented in this section (nine articles) covers a broader research area than the other five. It encompasses early concepts and ICT development models dealing with the digitalization of construction stakeholder management practices, i.e., collaboration and communication between stakeholders. Additionally, in this broader topic, we included articles which described advanced digital approaches to project and stakeholder management using multiple ICT systems. Thus, this first topic briefly introduces most of the ICT technologies and digitalized stakeholder management practices which are more thoroughly explained in the other five topics.

The other five topics have a strong focus on one ICT system. Assigning some articles to one research topic was challenging because they dealt with more than one ICT system. The criterion used to categorize articles was the main ICT technology used to perform stakeholder management, i.e., an article describing SNA analysis of the stakeholder network was placed in the SNA category, even though data were collected through social media, which represents another category. Another example is an article describing a virtual reality (VR) approach to designing review communication between end-users and designers that was placed in VR/AR, even though the initial VR model was based on a BIM model (e.g., BIM represents another topic). The approach to categorization is based on detailed qualitative insight in every analyzed article, leaving us with sufficient conviction that the articles are properly categorized.

The second topic (14 sources) presents web technology and web-based (cloud) applications, which provide a more comprehensive and formal approach to construction stakeholder management than any other ICT approach. Cloud applications in the construction industry can be grouped into three major groups: cloud computing (1) in construction management, (2) in design and engineering, and (3) in BIM [40]. Following this line of thought, we ascribed every article dealing with some form of web-enhanced BIM or VR to these other ICT systems (e.g., VR or BIM), which are primarily addressed. Thus, this second topic encompasses articles dealing specifically with the web as a primary ICT approach to stakeholder management. The third topic is BIM (15 articles), which is further divided into a subtopic dealing with a regular BIM approach to stakeholder collaboration and another dealing with BIM enhanced with web or some other technology (e.g., cloud-enhanced BIM). The fourth topic (10 articles) addresses a virtual and augmented reality (VR/AR) approach to the involvement and communication with construction project stakeholders. The fifth topic (seven articles) refers to social media as an ICT tool to manage the wider stakeholder community, and the sixth topic deals with social network analysis methods done through various software applications.

3.2.1. Various ICT Concepts, Approaches, and Tools to Digitalize Stakeholder Communication and Overall Management

This first category encompasses six papers dealing with concepts and the wider technological and organizational context of ICT implementation for purposes of stakeholder collaboration. Another three papers presented a broader approach to ICT implementation for stakeholder management purposes by elaborating the combined usage of a few different ICT tools.

Various ICT Concepts and Approaches to Digitalizing Stakeholder Communication and Analysis

The term groupware, dating from 1978, is defined as intentional group processes plus software, and a few different types of ICT systems that were later researched fell into this category, namely computer-supported cooperative work (CSCW), group decision-support 
systems (GDSS), and computer-mediated communication [41]. Papers dating to the early and mid-2000s emphasized communication as the key aspect of construction project management that was affected by ICT [24,41], and they dealt with issues of how to properly implement ICT for collaboration in order to increase productivity in various construction processes. Considering ICT through the perspective of critical social theory, Adrianesse et al. [22] concluded that contracts, different stakeholder interests, and the different language used by stakeholders influence ICT-supported communication activities and that it is very important to further develop ICT in a way that supports both strategic and normative regulated activities. Arayici et al. [42] analyzed computer integrated construction (CIC), which consists of ICT systems designed to facilitate collaboration between a geographically dislocated set of construction stakeholders (i.e., ICT tools for client briefing, site planning, etc.). They concluded that requirements engineering is necessary and a significant enabler for proper implementation because it brings a shared understanding between end-users (e.g., various stakeholders) of ICT systems. Similarly, Ahuja et al. [43] developed IT-enhanced communication protocols for building project management targeting small and medium enterprises (SME) because every supply chain member must use the same communication methods in order to achieve proper ICT-supported stakeholder collaboration. Marshall-Ponting and Aouad [41] developed the concept of the $\mathrm{nD}$ model, defined as an extension of the 3D building information model which would allow what-if analyses to be performed (i.e., knock-on effects for time, cost, etc.). They [41] envisioned VR as an ICT tool which should provide a means to visualize $\mathrm{nD}$ models and lead to the development of transdisciplinary thinking in design and construction by involving other stakeholders requirements (i.e., end users) in building models. A different type of ICT research stream consists of multi-agent systems (MAS) emerging from the artificial intelligence field, where the agent is a computer system that can act autonomously to reach its objectives, and it is used to analyze and simulate sophisticated patterns of interactions, such as cooperation or consensus [44]. Building on previously validated organizational simulation tools (e.g., MAS), Du and El-Gafy [45] developed the multiagent-based behavioral simulation model $\mathrm{ABM}$ to tackle the issue of goal incongruence between various stakeholders in the project proposal phase.

Implementation of Various Combined ICT Tools for Engagement and Collaboration of Project Stakeholders

In urban highway reconstruction, a major challenge is to balance the mobility needs of public stakeholders and the construction needs of the contractor [29]. In the case presented in [29], the transportation agency (e.g., the project owner of the highway project) made and disseminated nine 3D drive-through animations and a 4D animation (e.g., using various ICT tools) that virtually depicted the construction process of the project with upcoming activities, and they reported great improvements in the coordination and satisfaction of stakeholders. In one large metro rail project, ICT was used in the form of 3D CAD visualizations, traffic simulations, and social media comments to persuade stakeholders and reach mutual satisfaction [25]. Additionally, simulation and social media were used to frame some project events in a way that was mostly in line with solutions presented by the project team, and a third way of strategic use was to hegemonize the support of public stakeholders [25]. Zhou et al. [46] presented a framework for a smart construction site with its three key elements including an information support platform, collaboration work, and intelligent construction management, which included several ICT systems such as BIM, Internet of Things, GIS, etc. They highlighted the need for a good information support platform and greater transparency of site information for all project stakeholders in order to achieve innovative management modes which are more cooperative and productive.

3.2.2. Web Technology, Web-Based Applications, and ICT Tools as Means of Comprehensive Project Stakeholder Management

This topic includes 14 sources dealing with a web-based approach to stakeholder management. Eight articles covered a wide range of digital approaches to construction 
stakeholder management based on the web. Another six sources (e.g., two articles and four websites) analyzed two web-based applications which are made solely for the purpose of formalizing stakeholder management processes and practices.

Web Technology and Web-Based Applications Used to Digitalize a Variety of Different Stakeholder Management Practices

Early papers (late 1990s and early 2000s) refer to web-based ICT systems as those which use the Internet and the World Wide Web (WWW) [47,48]. One of those web-based ICT systems, "Total Information Transfer System" (TITS), enabled users to share text, graphics, audio, and video through "web pages" and "hypertext" links [47]. The most advocated benefits of web-based systems were enhanced information sharing and communication and the ability to generate cost savings through the usage of the Internet $[28,47]$. Similar to TITS, ProjectCentre was a web-based application used by project team members to manage correspondence, requests for information, instructions, variations, drawings, etc., and there was also a public area available where the general public could review "project newsletters" and other documents [48]. It is important to note that even early versions of web-based applications provided features to conduct management of both internal and external construction stakeholders. A large portion of ICT systems encompassed features suitable for the construction phase of a project, and the Construction Dynamic Teams Communication Management (Con-DTCM) system [28] was made specifically for small-tomedium sized subcontractors and suppliers, thus enabling general contractors to manage their stakeholders. Some features of Con-DTCM are a schedule management module, costs, assets, online communication, and multimedia, and there are many others. Chung et al. [30] analyzed computer-supported cooperative work (CSCW) platforms covering the same broad area of digital stakeholder communication and cooperation. However, they presented a collaborative client briefing framework, which the shifted focus of web-based applications to the early project development phase (e.g., client briefing), enabling users to visualize the whole "requirements identification" process in a graphical form. Wang and Zhang [49] presented a tailor-made web-based project management system (named ICPMS) developed for one major developer, and it encompassed a common communication platform for the project participants, coordinating the company headquarters, construction sites, and consultancy offices. Another similar type of web-based ICT consists of digital construction-phase information management (DCIM) systems, which were analyzed from the public client perspective (e.g., Departments of Transportation, DoTs), and respondents strongly agree that DCIM systems can improve an organization's overall business processes [2]. Web-based applications for the construction industry were primarily oriented toward the support of construction management actions, and features for construction project management that supported the management of broader project stakeholders were developed later.

Web ontology (or the semantic web) can be used to support heterogeneous data transfer and integration through web services; thus, to facilitate the collaboration and information exchange of supply chain stakeholders, an ICT system based on ontologies was developed, assisting stakeholders in using their own machines storing data but using a common platform, which improves data integrity [50]. A different approach focusing on quantifying data privacy, security, and performance was developed to test the adequacy of each web-based system linked in a federation of computational infrastructure from multiple stakeholders (e.g., architects, engineers), and this improved the on-time completion of projects and enhanced collaboration performance [51]

\section{Stakeholder Circle Tool and Darzin Software-ICT Tools for Stakeholder Management}

The Stakeholder Circle tool is primarily used for the visualization of stakeholders and their influence on a project $[12,19]$. Its key elements are concentric circle lines that indicate the distance of stakeholders from the project delivery entity, the size of the block and its relative area, which indicates the scale and scope of influence [12]. The Stakeholder Information Management System (SIMS) database is a sophisticated tool, based on the 
Stakeholder Circle tool and method, designed for the identification, analysis, and management of a single stakeholder community of a project, and it was transitioned to "the cloud" (SaaS or an organization's internal web server) [52]. It has many features such as recording of the stakeholder data, automatic calculation of their priority to the project, drawing of the stakeholder circle, etc., and it helps the project team to perform comprehensive stakeholder management.

Another even more comprehensive ICT tool for stakeholder management is Darzin software, which is similar to a CRM but specifically for managing stakeholders [53]. Darzin software is a robust tool which helps in mapping and segmenting stakeholders, keeping their details up to date, and it records all SM activities, so it is possible to look at which project team members have been interacting with a stakeholder, when, and what the topic was [53]. Furthermore, there is an option to create surveys and publish them on a website, and collecting stakeholder feedback is made simple; in addition, each type of project interaction with a stakeholder is easily traceable (i.e., an online discussion forum, a survey, a face-to-face meeting, or an email) [54]. Examples of Darzin software usage on real projects show its ability to lead stakeholder engagement through all project phases, i.e., a USD 10.9 billion Metro Tunnel mega project had very frequent consultation with its stakeholder community, which is shown in Darzin software engagement statistics (e.g., 19 community sessions, over 1500 attendees, 180 meetings, and 50 presentations, etc.) [55].

3.2.3. BIM Collaboration as Means of Engagement and Integration of Internal Construction Project Stakeholders

This section includes 15 BIM-related articles which are divided into two subsections. The first deals with regular BIM-supported collaboration of construction stakeholders, and the second subsection encompasses articles dealing with BIM collaboration enhanced by web and other ICT technologies.

Regular BIM Used for Integration and Collaboration of Construction Stakeholders

Many governments and authorities have openly accepted BIM in the construction industry to provide the required information exchange between stakeholders, and thus they have supported changes that should lead to increased productivity, efficiency, quality, reduction of costs, etc. [56]. One remote construction project architectural firm used BIM to collaborate with the main contractor and other personnel on site, which resulted in increased and very effective collaboration in comparison to prior remote projects [56]. Furthermore, one utility relocation project BIM 3D visualization enabled clash detection and coordination of designers and various utility stakeholders [57], and an in metro-rail project 3D visualization was successfully used to persuade external stakeholders to support the project's goals [25]. A BIM 4D simulation enabled the tracking of actual progress of relocation works and thus improved coordination in the construction phase [57]. In many cases of BIM usage, the benefit of better coordination is reported, and Maskil Leitan and Reychav [58] conclude that BIM leads to the formation of a new and possibly much more cooperative organizational infrastructure in which conducting proper stakeholder management can greatly contribute to project success. BIM influences stakeholders' framing of event patterns throughout project delivery because of changes occurring in information landscapes, i.e., sources and flows of information are different in BIM projects [59]. Some examples of good BIM implementation point to the high importance of the BIM managers and BIM coordinators in the project stakeholder network, demonstrating the effectiveness of these two new roles in managing the flow of communication [60]. Kapogiannis and Sherratt [61] refer to BIM as an integrated collaborative technology, and they discovered that these types of technologies can boost collaborative culture throughout a project. According to Mutis and Ramachandran [62], BIM technologies and teamwork should be configured to adapt to one another and enable the effective performance of distributed and collocated work tasks, which is often not the case. Kapogiannis and Sherratt [61] corroborate this line of thought and highlight the Chartered Institute of Building's conclusion that the construc- 
tion industry has failed to implement BIM maturity level 2 due to a lack of understanding of how to collaborate.

\section{Upgrading the BIM Collaborative Capabilities with Web and Other ICT Technologies}

To address the issue of cooperative work in BIM, Mutis and Ramachandran [62] developed the BIMbot cognitive assistant that informs and advises on activities, engages team members together in a task, and facilitates fundamental actions for shared understandings. The dialog-based agent design of BIMbot was based on machine learning algorithms, and it uses a combination of technologies and resources for the successful pro-active exchange of stakeholder dialogs [62]. With a similar intention, Lin et al. [63] developed a databasesupported and BIM-based CMI (DBCMI) system for general contractors which integrates BIM with web technology and allows users (e.g., project managers, BIM engineers, etc.) to communicate various interface issues. Cooperative scheduling which includes subcontractor contribution is a rarely adopted method because collaborative interfaces and ICT tools are not user friendly for new or inexperienced users, so Tallgren et al. [64] developed a web-based VPP application for collaborative BIM 4D scheduling which was used and evaluated on a real project case. Users stressed the improved legibility of the schedule as well as a better overview of the tasks and agreed that VPP really supports cooperative scheduling [64]. Another approach on a similar issue was the development of a web and database-supported visualization platform that enables real-time information sharing of daily $4 \mathrm{D}$ BIM. This platform enhanced communication and collaboration among project participants in comparison to a file-based 4D BIM approach [65]. The collaboration of stakeholders (i.e., suppliers) is fundamental to successfully achieve the objectives of precast construction within the allocated time and assigned cost, and this issue led to the development of a collaborative tool comprising cloud computing, building information modelling, and context awareness (e.g., CACCBIM) [66]. By considering important features of data ownership and privacy in a cross-party collaboration study, [67] proposed a multi-server approach based on a private cloud for BIM data sharing and management in which different stakeholders can collaborate smoothly while retaining ownership and control of their data. BIM and web technology might not be enough to significantly improve collaboration, so one case study implemented both public (shared room) and private workspaces (e.g., personal laptops with BIM for each stakeholder) [27]. The study showed that collaborative workspaces with direct and indirect communication channels indeed enhanced communication and collaboration [27]. Another study that came from interactive workspaces similarly concluded that the exchange of product BIM models needs to be complemented with easy-to-use, easy-to-set-up information sharing and interaction approaches [68].

3.2.4. Virtual and Augmented Reality (VR/AR) as Means to Enhance Collaboration in Design Phase and Involve End-Users in Early Project Phases

There is evidence indicating that current communication practices fail to meet the requirements of increasingly complex projects, and a trend of creating a digital communication environment between stakeholders has been noted [69]. The AR/VR market in the United States could be as large as USD 182 billion by 2025, proving that VR is a versatile tool for creating a collaborative environment [70]. Communication tools and affordance in AR/VR are manifested through several forms: text-based tools, voice chat tools, visual sharing affordances, and avatars [69]. VR provides a shared visualization of information and immersive environment for users to explore, communicate, and meet with others [69] and thus alleviates the issues of visualization on mediums such as computer screens which lack some degree of immersion [71]. Another problem with conventional collaboration methods such as BIM-Big room is the need for the physical presence of participants in a room [71], while VR allows geographically dislocated stakeholders to collaborate [58,59]. Balali et al. [70] propose a VR-based framework for interior finish material selection, incorporating both visual aesthetics and associated cost impacts. Through their method [70], they offer stakeholders an interactive and immersive environment to interact with a three-dimensional model and visually receive an updated cost estimate in real 
time, thus providing benefits such as end-user design involvement, end-user satisfaction, and reduction of design changes. Anderson et al. [72] discovered that avatar movement and position were effective at communicating the non-verbal information of stakeholders and that collaboration was enhanced when gesture bubbles were used for backchannel communication. Chalhoub and Ayer's [73] results suggest that mixed reality (MR) used as a construction site tool enabled a significantly higher productivity rate; reduced the time required to understand the design; led to fewer errors; and increased the number of accurately constructed conduits, thus showing that it improves the engagement of site personnel. Project communication was enhanced by Dinis et al.'s [74] new workflow, which coupled laser scanning and virtual reality (VR) within building information modelling (BIM) and brought an alternative approach regarding the definition of expected requirements, qualities, and specifications valued by stakeholders (i.e., project owners). Similarly, Ventura et al. [75] formed a process map representing all the necessary phases and activities to consider for the effective adoption of immersive VR to evaluate design intents with clients and end-users. The investigation of Abbas et al. [76] showed no large statistical difference in IVR-based and face-to-face (FtF) communication in terms of discussion quality, communication richness, and openness, but $\mathrm{FtF}$ did show slightly better results, and this led to the conclusion that immersive reality needs improvement to better represent realistic interactions. The issue mentioned concerning interactions in VR motivated Du et al. [40] to introduce a cloud-based multiuser VR headset system called collaborative virtual reality (CoVR) with the option of face-to-face conversations in the virtual world, which helped project stakeholders create a shared vision.

\subsubsection{Social Media as Modern Means to Engage Public Stakeholders and Internal Project Team}

Social media platforms have become omnipresent in our daily life, and this is due to their convenience of use; users access social media from their smartphones at any time and from any place [77]. Social media entered into the field of project management, and it has been increasingly used in communication with construction project stakeholders [77]. Some scholars predict that new digital ways of communication will transform project stakeholder management, providing both opportunities and challenges [78]. The most common use of social media has been reported in the engagement of public stakeholders [25,79], which is corroborated by the fact that the usage of social media is constantly on the rise in large U.S. state transportation agencies [80]. Minooei et al.'s [80] survey on the STA's personnel showed that social media is ranked high in both effectiveness and frequency of usage and that it is considered highly effective in building trust among stakeholders. Furthermore, social media (e.g., Twitter) can help to handle the complexity of soft and context-sensitive issues for modern urban infrastructure [81] because it encourages the micro-participation of numerous public stakeholders (i.e., citizens) [82]. Ninan et al. [25] showed an example of how social media was strategically used to influence the project community, and Ojelabi et al. [83] examined the social media practices of construction companies and concluded that their implementation is very basic, lacking the elements of serious stakeholder management based on social media. The challenges of using social media (i.e., Facebook, Twitter) for consulting and informing public stakeholders must be taken seriously because there is a risk of a perceived lack of responsiveness [78]. Al-Shehan and Assbeihat [77] pointed to the fact that project managers are increasingly using various types of social media for management of their internal team because it is a very efficient (fast with low cost) way to carry out information. Beyond a communication tool, online social media can be used for the analysis of connectivity among project stakeholders and can help to understand the typology of a project's online followers by segmenting their vested interests [82], while combining it with existing approaches provides a stronger basis for planning management strategies [84]. 
3.2.6. Social Network Analysis for Robust Pre- and Post-Engagement Analysis of Stakeholders

The concept of social network analysis (SNA) developed out of social network theory, and its application incorporates mathematical, statistical, and computing methodologies [85]. Furthermore, SNA is based on methods and tools of graph theory [86], and various software packages can be used to visualize the relationship network, including UCINET, NetMiner, NetDraw, Pajek, etc. [85]. Social network analysis is used by project managers when they want to understand how the interaction in the project occurs, how strong the connections are between team members, who is the key stakeholder, etc. [86], and Doloi [87] points out that prior to analysis, stakeholders should be identified, i.e., by their project roles. Mok et al. [88] used SNA in cultural building projects to recognize the key actors and critical stakeholder concerns, while Almahmoud and Doloi [89] used it to map stakeholders with respect to their relative stakes and seven social core functions. In different contexts, SNA was used either to identify key stakeholder(s) $[49,87,90]$, which requires an analysis of network node characteristics, or to analyze the whole inter-organizational communication network [91,92], which focuses on overall network measures. Usually, communication data are extracted from a project and used as input to SNA software calculations, and these data can be based on, i.e., plotting the contractual stakeholder relations for analysis prior to conducting stakeholder engagement or combining it with real project communication for post evaluation purposes [91]. Various other stakeholder and/or project characteristics can also be input into SNA, i.e., stakeholder power [93]. SNA was also used with other methods to provide even more insightful stakeholder analysis, i.e., it was combined with a social performance index [94], and in another example, it was combined with Louvain's algorithm in what if analysis to predict situations if other stakeholders are invited to the project network [95]. Furthermore, Yu et al. [96] used SNA to investigate the social risks related to housing demolition from a stakeholder perspective, and their inputs in this merged stakeholder-risk analysis were stakeholder-associated risks. Nik-Bakht and El-Diraby $[79,92]$ analyzed project discussion networks on social media and conducted analysis for different project stages to unveil the relevance of public stakeholder management to the whole life cycle of construction projects. They concluded that community inputs and interactions are becoming critical criteria for project management, and SNA is a great help in making sense of complex project stakeholder networks.

\section{Discussion-The Need for Digital Transformation to Enable Digitalized Construction Stakeholder Management}

\subsection{Various ICT Concepts and Approaches to Digitalize Stakeholder Communication and Management}

In this broad topic, many papers have dealt with the question of how to implement and develop new ICT systems and how to obtain the most out of recently developed advanced digital technologies. In the case of the presented multiagent systems (MAS), there is a need for external justification to increase the applicability of developed simulation systems [45]. There is also merit in further investigation of integrating MAS and other ICT systems such as BIM [44]. Even though visualization and simulation have brought obvious benefits to project managers in terms of stakeholder management, public relation savings, and smoother stakeholder relations $[25,29]$, there is still the question of proving the value for money. The responsibility to justify expenses in ICT infrastructure, which can be relatively high, opens up the research question of how to calculate the cost-benefit analysis of implementing various ICT systems [29].

The need for alignment of ICT and common communication protocols in construction project management is highlighted [24], and authors are pointing to the fact that without people first fully embracing the concept, ICT will not contribute much. They have stated the need for structural cooperation between ICT vendors and user companies [24], which can be interpreted as a call for greater involvement of construction industry stakeholders in the development of ICT systems designed for them. This is in line with other research in this field [41,43], which has emphasized the need for a user-centered approach to 
the development and implementation of ICT systems, which covers collaborative work between various construction stakeholders. Marshall-Ponting and Aouad [41] concluded that short-termism and the adversarial nature of the construction industry are deemed to be the biggest barriers to implementation, but also warned that it is crucial to carefully manage the expectations of industry professionals concerning new ICT and thus to prevent disappointment. A few combined ICT systems were tested for the purpose of managing construction site stakeholders [46], and the study suggested that the focus should be on how to tailor ICT systems to ensure effective collaborative work among different participants, because even with a carefully planned collaborative system, there are still difficulties with managing the ICT collaboration of multiple firms.

\subsection{Web Technology, Web Applications, and ICT Tools as Means of Comprehensive Project Stakeholder Management}

There are calls for the development of more innovative ICT tools and improvements in implementation procedures, but issues of cultural barriers and difficulties of changing the traditional way of working in the construction industry are still present [48]. This very much resounds the same issues mentioned in the previous section. Furthermore, there is the problem of initial costs for setting up new ICT systems and additional time [28,30], but also there is evidence that the savings from using web technology to enhance collaboration achieved throughout the projects is greater than the costs. The experiences of some ICT implementations are still showing signs that web-based applications are not tailored enough for multiple firm usage [2], and furthermore, many firms are in the category of SME and thus unable or unwilling to pay usage fees [28]. There is room to further explore how to make web apps cheaper and more available for widespread usage. Additionally, the authors of $[30,51]$ admit that newly developed frameworks and models (e.g., the client briefing framework or federated cloud evaluation) are better suited for large scale projects and multiple stakeholder contexts, leaving room to explore web apps for normal scaled projects. For stakeholder circle apps, there is room for improvements in terms of adding visualization of stakeholder networks [12] and also the question of whether the stakeholder management process should be somehow merged with risk management [97]. Darzin software seems to be the real deal in a comprehensive digitalized approach to stakeholder management, but the only reports in usage come from Australia [13]. It could be concluded that even though web applications and web technology seem to be very robust, widespread adoption has not occurred, which is the opposite to dominant scholarly predictions in early 2000, when most of the community thought that web technology would swiftly and radically transform management practices.

\subsection{BIM Collaboration as Means of Engagement and Integration of Internal Construction Project Stakeholders}

Many benefits are advocated in the case of BIM implementation, but projects with BIM face organizational challenges that limit collaboration, which led to the conclusion that external assistance may be required to change the status quo [56]. Project change management processes in BIM projects have shown that if we want to perform BIMsupported change management there, it can only be done if we re-engineer construction change management processes, adjusting both the workflow and the organizational units involved [98]. Liu et al. [59] echo the BIM-coordinating architect they interviewed that it is not right to bear the responsibility for the BIM model if other project participants drew it, and they conclude that there are too many unaddressed obligation issues in current BIM practices. To achieve benefits from the BIM collaboration of project stakeholders, besides alignment with the work activities, a willingness to adopt BIM is also considered as a crucial factor [57]. The novel IPD delivery system has proven advantageous in assuring smooth BIM collaboration; nevertheless, a separation between technological coordination and IPD team management should be made, and there is a need to properly manage stakeholders in this project setting [58]. Future research should also analyze the cost benefits for, i.e., web-based BIM 4D scheduling [65] and devise methods to translate the collaboration 
leverages of interactive public workspaces in the distributed meetings domain [27,68]. Godager et al. [99] presented the emerging enterprise BIM organization concept (EBIM) and emphasized the need for ICT standardization and best practices for interdisciplinary collaborative projects. Shrahily et al. [100] conclude that communication remains a major issue to achieve BIM Level 3 in the UK, as it requires all organizations involved to use a single platform to facilitate communication, which further corroborates the need to develop the proper organizational context for multi-firm collaboration in BIM.

\subsection{Virtual and Augmented Reality (VR/AR) as Means to Enhance Collaboration in Design Phase and Involve End-Users in Early Project Phases}

The usage of virtual reality and similar technologies (e.g., AR and MR) has risen in recent years, but it is still relatively new ICT in the AEC industry, and at this stage of development, technology is quite expensive [40,76]. Zaker and Coloma [71] highlighted that further research and development should deal with making these technologies more affordable, while Ventura et al. [75] call for an appropriate framework for measuring the actual added value of VR systems implementation. There is room for various improvements to make VR/AR more adjusted to the communication needs of AEC industry stakeholders [71], and one research stream should deal with improving the accuracy of the data collected and analyzed in such environments so that they represent physical environments more realistically $[69,101]$. Current VR/AR affordances (i.e., text-based chat, avatars, etc.) proved to be useful, but there is still a need to develop more affordances to better meet stakeholder communication requirements $[69,76]$. Future works in the field must also be focused on the education of students and industry professionals to enhance overall awareness within the AEC industry stakeholders [71]. Additionally, it is very important to avoid focusing more than necessary on technological aspects, because there is a great importance to include a procedural perspective in research, which should address issues such as contractual aspects of VR adoption in design review meetings in relation to the validity of the VR representation, considering both the level of information need and the stakeholders involved in the analysis [75].

\subsection{Social Media as Modern Means of Engagement for Public and Community Stakeholders}

Social media has proven to be a modern tool for the engagement of various stakeholder groups because of its widespread usage for communication and sharing of various types of information. Ojelabi et al. [83] concluded that social client relationship management (CRM 2.0) based on social media is not recognized in the construction sector, while it is often used in various other industries. According to this study [83], even if the concept of CRM 2.0 is implemented in a construction business, lack of control and lack of effective communication of protocols to employees are potential threats to business, which is in line with some other suggestions that it would be advisable to regulate and professionalize social media usage as a stakeholder management tool [77]. Al-Shehan and Assbeihat [77] advise project managers to fuse offline and online strategies to improve more effective stakeholder management, which is in line with Ninan et al.'s [25] predictions that social media usage for external stakeholder management can vastly contribute to successful engagement. Williams et al.'s [84] findings indicate that the majority of online stakeholders opposed the observed project, and they formed stable clusters that were not prone to a change of heart no matter what engagement strategy was used, probably because the engagement of the affected community started too late. Conducting an analysis of stakeholder concerns using, i.e., Twitter in order to improve the planning of public stakeholder engagement can be misleading because there are always groups who are not vocal in an online environment or simply are not active with particular social media (i.e., Twitter) [81], and there is also the issue of confidentiality of the project-related as well as follower-related information [82]. More detailed insight into stakeholder engagement through social media monitoring of online communication must be applied as a continuous process over different phases of the project, and measures should be improved to focus on closer types of connection and stronger ties among project followers, e.g., observing the number of retweets [82]. 


\subsection{Social Network Analysis for Robust Pre-and Post-Engagement Analysis of Stakeholders}

Lin et al. [93] caution on the generalizability of SNA analysis and point out that it can only show the general perceptions of stakeholder power, because under different project delivery approaches or different project types, the distribution of stakeholders' power and responsibility varies significantly. Mok et al. [88] echo with a similar caution and advise performing multiple analyses with different types of stakeholder-related data to cover all the angles of a project. Yu et al. [96] extended SNA to the area of social risk management and indicated that stakeholder analysis and management can be integrated with other project management tools (e.g., risk management) to provide a more robust way of dealing with stakeholder-associated issues. On the other hand, Trach et al. [95] recommend that the analysis of communication networks should be done several times throughout the project and point to the possible weaknesses of the SNA network centrality measure, proving that the centrality of certain stakeholders can be artificially high in situations where neighboring nodes have a very weak centrality. The application of social network analysis requires a comprehensive understanding of the actors (stakeholder groups) and their relationships to other project stakeholders, which is much more time consuming, complex, and costly than traditional stakeholder analysis; thus, to ease the data collection process, it should be planned from early phases. Yang [85] concludes that no one method for stakeholder analysis is perfect and that applying both empirical and rationalistic (e.g., software SNA analysis) perspectives and comparing the analysis results when necessary is the best way to analyze stakeholders.

\subsection{Summary Analysis of Presented Digital Approaches to Stakeholder Managemnet}

To summarize the status of the six research topics identified for the field of digitalized construction stakeholder management, we organized the information in the form of the current status of each topic and suggestions for further studies (Table 4).

Table 4. Current status and future directions for digitalization of construction stakeholder management.

\begin{tabular}{|c|c|c|}
\hline Current Status & Research Topics & Needs for Further Studies \\
\hline $\begin{array}{l}\text { 1. Stakeholder communication is currently the } \\
\text { most affected engagement practice by ICT } \\
\text { 2. Models, approaches, and protocols are being } \\
\text { researched as organization enablers of stakeholder } \\
\text { management digitalization } \\
\text { 3. Mixed usage of ICT supported simulation, } \\
\text { visualization, and communication can be effective } \\
\text { 4. ICT infrastructure tailored to specific project and } \\
\text { transparency of information are important } \\
\text { organizational enablers }\end{array}$ & $\begin{array}{l}\text { Various ICT concepts, } \\
\text { approaches, and tools to } \\
\text { digitalize stakeholder } \\
\text { communication and } \\
\text { overall management }\end{array}$ & $\begin{array}{l}\text { 1. Providing ways to determine cost and } \\
\text { other benefits of ICT implementation for } \\
\text { stakeholder engagement } \\
\text { 2. Need to tailor ICT tools and systems to } \\
\text { current needs of construction stakeholder } \\
\text { and to make them user-friendly } \\
\text { 3. Need to tailor ICT to support } \\
\text { collaborative work in multi-firm context }\end{array}$ \\
\hline $\begin{array}{l}\text { 1. Web applications come in various forms and } \\
\text { primarily serve for information and } \\
\text { communication management } \\
\text { 2. Web technology is one of the first ICT tools for } \\
\text { stakeholder management } \\
\text { 3. Different web applications are tailored for } \\
\text { different types of stakeholders } \\
\text { 4. Semantic web and web platforms are emerging } \\
\text { as means to increase digital cooperative } \\
\text { capabilities of construction stakeholders } \\
\text { 5. Two web applications are made specifically to } \\
\text { digitalize overall stakeholder management process }\end{array}$ & $\begin{array}{c}\text { Web technology, web-based } \\
\text { applications, and ICT tools } \\
\text { as means of comprehensive } \\
\text { project } \\
\text { stakeholder management }\end{array}$ & $\begin{array}{l}\text { 1. Tailor web application for regular size } \\
\text { project and business as usual } \\
\text { 2. Develop ways for widespread adoption } \\
\text { of developed web applications } \\
\text { 3. Develop means to re-engineer current } \\
\text { project and stakeholder management } \\
\text { practices and processes which are proven } \\
\text { to be effective in web-based } \\
\text { working environment }\end{array}$ \\
\hline
\end{tabular}


Table 4. Cont.

Current Status
1. BIM can improve information exchange
between internal stakeholders if used properly
2. BIM collaboration is often hindered by improper
BIM implementation in usual construction
project settings
3. Collaborative capabilities for real-time
cooperation are being developed through various
ICT technologies as add-ons to BIM systems
4. Collaborative workspaces as organizational
enablers of BIM project collaboration

Research Topics
BIM collaboration as means of engagement and integration of internal construction project stakeholders

1. VR/AR as a tool for engagement of end-users and other stakeholders through visualization in immersive environment

2. Various affordances of VR/AR technology are being researched to improve communication and engagement capabilities

3. Scarce synchronization of information in

VR/AR environment and BIM model

4. Web technology as VR/AR add-on to improve its collaborative capabilities

\author{
Virtual and augmented \\ reality $(\mathrm{VR} / \mathrm{AR})$ as means to \\ enhance collaboration in \\ design phase and involve \\ end-users in early \\ project phases
}

\section{Needs for Further Studies}

1. Need to re-engineer construction processes to enable BIM cooperative capabilities

2. Implement new and adjust current practices of communication and management of project stakeholders in specific delivery systems supporting BIM (i.e., IPD)

3. Need to further explore cost to benefit ratio of implementing web technology add-ons and collaborative workspaces to increase BIM collaborative capabilities

1. Need to make VR/AR technology affordable and user friendly to achieve its collaborative potential

2. Need to enhance education, training, and overall knowledge of industry professionals

3. Need to further explore procedural perspective and process reengineering to better suit VR/AR collaborative capabilities to construction processes
1. Social media as effective ICT tool for engagement of public and community stakeholders

2. Recognition of social media potential for internal project communication

3. Recognition of social media potential for analysis of external stakeholders.

\section{Social Media as modern means of engagement for public and community stakeholders}

1. Need to further explore and implement social media (collaborative capabilities) to formal stakeholder management process

2. Need to devise ways of how to mix social media communication with other engagement strategies
1. SNA is visualization tool used for robust stakeholder analysis of stakeholder networks, and it comes in several software packages

2. Visualization of relationship network and SNA calculation are both used prior to stakeholder engagement and as post-engagement evaluation 3. Nature of data used as SNA input and subject of stakeholder analysis are key success factors for SNA analysis

\author{
Social network analysis for \\ robust pre- and \\ post-engagement analysis \\ of stakeholders
}

1. Need to devise ways of how to mix social network analysis with other methods of stakeholder analysis

2. Summarize all SNA analysis capabilities for various stakeholder characteristic and joint stakeholder-risk analysis

3. Need to devise ways to increase knowledge about SNA and project data collection to enable widespread adoption

Each specific research topic has contributed to the overall goal of examining the means of digitalizing stakeholder management practices in the construction industry. There are various ICT systems and approaches to digitalize stakeholder analysis and engagement practices, which are identified in this research. It can be concluded that engagement practices of stakeholder communication and collaborative working of a few stakeholders in the project were the most researched stream of digitalization. Even though each research topic has its own research streams for which we suggested future directions (Table 4), it is possible to give some remarks for the whole research area of stakeholder management digitalization. Suggestions and the need for further research on all six topic leads to these concluding remarks for future work in this field:

- $\quad$ BIM (3D/4D/5D), SNA, and web-based applications as a means to digitalize stakeholder management are more mature research streams than social media and VR/AR.

- $\quad$ There is a need to make ICT systems more user friendly (especially for inexperienced users) and more prone to construction practices. 
- There is a need to re-engineer and digitally transform some construction processes to enable further digitalization and effectiveness of digital technologies and systems.

- There is a need to make wider changes in terms of organizational and project policies and procedures (i.e., procurement) to unleash collaborative abilities of new digital technologies.

These results should be carefully interpreted as we acknowledge research limitations inherent in this research. First, the information source and search strategy have their limitations. Some researchers choose leading journals or mix them with databases, and some use only databases. We chose the latter and searched the two largest databases in our field. Because of this decision, certain relevant publications may not have been included in this review. Second, the retrieving process has an inherent risk of bias in terms of the exclusion procedure to arrive at the final set of the literature. We followed PRISMA methodology, and we devised a comprehensive coding scheme, but it is not possible to completely avoid the risk of bias in the exclusion process. Third, the keyword search has its limitations which can affect these results. Fourth, the review process itself can be biased based on researcher knowledge and personal viewpoint, which we tried to reduce by having two researchers reviewing independently and iteratively. Despite these limitations, we think that the results and new insights provided in this research contribute to the knowledge of how digitalization and digital transformation affect the way stakeholders behave, engage, and communicate in projects.

\section{Conclusions}

The objective of this article was to investigate digitalization as a process of transforming the management of stakeholders in construction. As shown, the stakeholder management practices are divided into analysis and engagement processes, and these processes are further divided into practices of stakeholder communication, collaboration, involvement, etc. We examined and organized knowledge in this broad field of digital performance of stakeholder management practices, which was done through a systematic literature review approach. In the final analysis, 73 sources were examined through descriptive and qualitative content analysis. Results were presented along with suggestions for and the needs of future studies.

In this study, we have found that the construction industry stakeholders often have problems in communication and collaboration in projects, which is a result of various organizational and technological factors. Digitalization was presented as a solution to these problems, but it did not deliver on its promises. There are various ICT systems and technologies used for digital stakeholder management, but it seems that examples of successful implementation of stakeholder collaboration and management through ICT systems are scarce. Additionally, much of the industry is not rushing to implement new digital ways of working, which is evident from reports placing the construction industry as one of the least digitalized.

From our research process, we excluded numerous articles dealing solely with technological aspects of ICT (e.g., standards for software interoperability), which points out that the technological context (e.g., diversity of ICT systems, tools, and underlying technologies) was broadly addressed in the literature. Our insights from the analysis of the retrieved literature, however, shows that organizational factors are those which prevent construction stakeholders from discovering the true potential of digital collaboration. For example, contractor firms need to first raise their organizational competencies for planning and scheduling in digital form to be able to engage in digitalized cooperative planning in projects. The same is true for collaborative designing in BIM, where each architectural and engineering firm should have considerable experience and competence in BIM 3D modelling to engage in this type of collaboration. Even for the narrower use of digital collaboration on 3D models (i.e., view 3D visualization and input textual comments), organizations such as public owners (e.g., transportation agencies) must restructure some 
internal processes and train their employees to be able to digitally collaborate with other project stakeholders.

Furthermore, organizational factors affecting poor digitalization are tied to obsolete business processes of firms working in construction projects, which hinders the ability of each stakeholder (e.g., individual or organization) to properly share information and communicate with other stakeholders. For example, BIM and virtual reality can indeed help in engaging end users early (i.e., design development), but owners and designers must explore and develop new processes and abilities to really be able to engage other stakeholders properly. Additionally, social media is a very present means of the everyday interactions of most individuals, and it is used in some projects as part of a digital client relationship management process (so-called CRM 2.0) [83]. However, again, results show [25,83] that the benefits of social media are not so high in construction projects because digital business processes such as CRM 2.0 are not very common in construction industry organizations.

The importance of digital transformation or, say, wider process and organization re-engineering is paramount, and this was especially seen in the last couple of years when digital collaboration was unavoidable (i.e., the COVID-19 crisis). Finally, it is obvious that industry-wide changes are yet to come, and the way to enable them is to investigate how to make ICT more user friendly and how to devise organizational and project processes which are more prone to digital collaboration between construction stakeholders.

Author Contributions: Conceptualization, K.R.P. and M.V.; methodology, K.R.P. and M.V.; formal analysis, K.R.P. and M.V.; investigation, K.R.P.; writing-original draft preparation, K.R.P.; writingreview and editing, K.R.P. and M.V.; visualization, K.R.P.; supervision, M.V.; All authors have read and agreed to the published version of the manuscript.

Funding: This research received no external funding.

Institutional Review Board Statement: Not applicable.

Informed Consent Statement: Not applicable.

Data Availability Statement: Not applicable.

Conflicts of Interest: The authors declare no conflict of interest.

\section{References}

1. Gustavsson, T.K.; Samuelson, O.; Wikforss, Ö. Organizing It in Construction: Present State and Future Challenges in Sweden. J. Inf. Technol. Constr. 2012, 17, 520-553.

2. Jahanger, Q.K.; Louis, J.; Pestana, C.; Trejo, D. Potential Positive Impacts of Digitalization of Construction-Phase Information Management for Project Owners. J. Inf. Technol. Constr. 2021, 26, 1-22. [CrossRef]

3. Gustavsson, T.K. New Boundary Spanners: Emerging Management Roles in Collaborative Construction Projects. Procedia Econ. Financ. 2015, 21, 146-153. [CrossRef]

4. Chassiakos, A.P.; Sakellaropoulos, S.P. A Web-Based System for Managing Construction Information. Adv. Eng. Softw. 2008, 39, 865-876. [CrossRef]

5. Björk, B. Electronic Document Management in Construction-Research Issues and Results. J. Inf. Technol. Constr. 2003, 8, 105-117.

6. Wikforss, Ö.; Löfgren, A. Rethinking Communication in Construction. Electron. J. Inf. Technol. Constr. 2007, 12, 337-345.

7. Agarwal, R.; Chandrasekaran, S.; Sridhar, M. Imagining Construction's Digital Future. Available online: https://www. mckinsey.com/ \{\}/media/McKinsey/Industries/Capital\%20Projects\%20and\%20Infrastructure/Our\%20Insights/Imagining\% 20constructions\%20digital\%20future/Imagining-constructions-digital-future.pdf (accessed on 1 November 2021).

8. Damstrom, M. Digitalization and Construction Project Management-What Consequences the Use of ICT-Tools Has Had on the Project Manager Role in the Construction Industry. Master's Thesis, Royal Institute of Technology, Stockholm, Swedish, 2020.

9. Jacobsson, M.; Linderoth, H.C.J. User Perceptions of ICT Impacts in Swedish Construction Companies: “It's Fine, Just as It Is". Constr. Manag. Econ. 2012, 30, 339-357. [CrossRef]

10. Daniotti, B.; Gianinetto, M.; Della Torre, S. Digital Transformation of the Design, Construction and Management Processes of the Built Environment; Springer Open: Cham, Switzerland, 2020. [CrossRef]

11. Kumaraswamy, M.; Wong, K.K.W.; Chung, J. Focusing Megaproject Strategies on Sustainable Best Value of Stakeholders. Built Environ. Proj. Asset Manag. 2017, 7, 441-455. [CrossRef]

12. Walker, D.H.T.; Bourne, L.M.; Shelley, A. Influence, Stakeholder Mapping and Visualization. Constr. Manag. Econ. 2008, 26, 645-658. [CrossRef] 
13. Yang, J.; Shen, G.Q.; Bourne, L.; Ho, C.M.; Xue, X. A Typology of Operational Approaches for Stakeholder Analysis and Engagement. Constr. Manag. Econ. 2011, 29, 145-162. [CrossRef]

14. Bal, M.; Bryde, D.; Fearon, D.; Ochieng, E. Stakeholder Engagement: Achieving Sustainability in the Construction Sector. Sustainability 2013, 5, 695-710. [CrossRef]

15. Uribe, D.F.; Ortiz-Marcos, I.; Uruburu, Á. What Is Going on with Stakeholder Theory in Project Management Literature? A Symbiotic Relationship for Sustainability. Sustainability 2018, 10, 1300. [CrossRef]

16. Cvijović, J.; Obradović, V.; Todorović, M. Stakeholder Management and Project Sustainability—A Throw of the Dice. Sustainability 2021, 13, 9153. [CrossRef]

17. Yang, R.J.; Shen, G.Q.P. Framework for Stakeholder Management in Construction Projects. J. Manag. Eng. 2015, $31,04014064$. [CrossRef]

18. Olander, S. Stakeholder Impact Analysis in Construction Project Management. Constr. Manag. Econ. 2007, 25, 277-287. [CrossRef]

19. Bourne, L.; Walker, D.H.T. Visualising and Mapping Stakeholder Influence. Manag. Decis. 2005, 43, 649-660. [CrossRef]

20. Prebanic, K.R.; Burcar Dunovic, I. Re-Investigating Approaches on Defining Stakeholder Characteristics. In Proceedings of the 13th International Conference Organization, Technology and Management in Construction Conference Proceedings, Poreč, Croatia, 27-30 September 2017.

21. Chinyio, E.A.; Akintoye, A. Practical Approaches for Engaging Stakeholders: Findings from the UK. Constr. Manag. Econ. 2008, 26, 591-599. [CrossRef]

22. Heravi, A.; Coffey, V.; Trigunarsyah, B. Evaluating the Level of Stakeholder Involvement during the Project Planning Processes of Building Projects. Int. J. Proj. Manag. 2015, 33, 985-997. [CrossRef]

23. Project Management Institute. A Guide to the Project Management Body of Knowledge (PMBOK®Guide), 5th ed.; Project Management Institute: Newtown Square, PA, USA, 2013.

24. Adriaanse, A.M.; Voordijk, H.; Dewulf, G. Alignment between ICT and Communication in Construction Projects. Int. J. Hum. Resour. Dev. Manag. 2004, 4, 346-357. [CrossRef]

25. Ninan, J.; Mahalingam, A.; Clegg, S.; Sankaran, S. ICT for External Stakeholder Management: Sociomateriality from a Power Perspective. Constr. Manag. Econ. 2020, 38, 840-855. [CrossRef]

26. Liu, Y.; Liu, Y.; Lin, M.; Zhang, J.; Yang, C.; Huang, G.; Zhang, Y.; Zhao, Q. Research on Application of BIM 5D in Communication of Project Muti-Participants-A Case Study of Nagpur Metro Project. In IOP Conference Series: Earth and Environmental Science; IOP Publishing: Bristol, UK, 2020; Volume 568.

27. Bassanino, M.; Fernando, T.; Wu, K.C. Can Virtual Workspaces Enhance Team Communication and Collaboration in Design Review Meetings? Archit. Eng. Des. Manag. 2014, 10, 200-217. [CrossRef]

28. Lin, Y.C. Development of Web-Based Teams Management System in Construction. World Acad. Sci. Eng. Technol. Int. J. Inf. Commun. Eng. 2010, 4, 129-134. [CrossRef]

29. Khwaja, N.; Schmeits, C. Improving the Transparency of Construction Projects Through Visualization Technology. Transp. Res. Rec. J. Transp. Res. Board 2014, 2408, 34-43. [CrossRef]

30. Chung, J.K.H.; Kumaraswamy, M.M.; Palaneeswaran, E. Improving Megaproject Briefing through Enhanced Collaboration with ICT. Autom. Constr. 2009, 18, 966-974. [CrossRef]

31. Obradović, V.; Montenegro, A.; Bjelica, D. Digital Era and Project Manager's Competencies. Eur. Proj. Manag. J. 2018, 8, 4-9. [CrossRef]

32. Fink, A. Conducting Research Literature Reviews: From the Internet to Paper, 4th ed.; SAGE Publications Inc.: Thousand Oaks, CA, USA, 2014. [CrossRef]

33. Denyer, D.; Tranfield, D.; Ernst van Aken, J. Developing Design Propositions through Research Synthesis. Organ. Stud. 2008, 29, 393-413. [CrossRef]

34. Moher, D.; Liberati, A.; Tetzlaff, J.; Altman, D.G.; The PRISMA Group. Preferred Reporting Items for Systematic Reviews and Meta-Analyses: The PRISMA Statement. Int. J. Surg. 2010, 8, 336-341. [CrossRef] [PubMed]

35. Seuring, S.; Gold, S. Conducting Content-Analysis Based Literature Reviews in Supply Chain Management. Supply Chain Manag. Int. J. 2012, 17, 544-555. [CrossRef]

36. Laplume, A.O.; Sonpar, K.; Litz, R.A. Stakeholder Theory: Reviewing a Theory That Moves Us. J. Manag. 2008, 34, 1152-1189. [CrossRef]

37. Alaloul, W.S.; Alzubi, K.M.; Malkawi, A.B.; Al Salaheen, M.; Musarat, M.A. Productivity Monitoring in Building Construction Projects: A Systematic Review. Eng. Constr. Archit. Manag. 2021. Epub ahead of print. [CrossRef]

38. Fellows, R.; Liu, A. Research Methods for Construction, 3rd ed.; Blackwell Publishing Ltd.: Oxford, UK, 2008.

39. Winch, G.M. Managing Construction Projects; Wiley-Blackwell: Chichester, UK, 2010. [CrossRef]

40. Du, J.; Shi, Y.; Zou, Z.; Zhao, D. CoVR: Cloud-Based Multiuser Virtual Reality Headset System for Project Communication of Remote Users. J. Constr. Eng. Manag. 2018, 144, 04017109. [CrossRef]

41. Marshall-Ponting, A.J.; Aouad, G. An ND Modelling Approach to Improve Communication Processes for Construction. Autom. Constr. 2005, 14, 311-321. [CrossRef]

42. Arayici, Y.; Aouad, G.; Ahmed, V. Requirements Engineering for Innovative Integrated ICT Systems for the Construction Industry. Constr. Innov. 2005, 5, 179-200. [CrossRef] 
43. Ahuja, V.; Yang, J.; Shankar, R. IT-Enhanced Communication Protocols for Building Project Management. Eng. Constr. Archit. Manag. 2010, 17, 159-179. [CrossRef]

44. Liang, X.; Shen, G.Q.; Bu, S. Multiagent Systems in Construction: A Ten-Year Review. J. Comput. Civ. Eng. 2016, 30, 04016016. [CrossRef]

45. Du, J.; El-Gafy, M. Using Agent-Based Modeling to Investigate Goal Incongruence Issues in Proposal Development: Case Study of an EPC Project. J. Manag. Eng. 2015, 31, 05014025. [CrossRef]

46. ZHOU, H.; WANG, H.; ZENG, W. Smart Construction Site in Mega Construction Projects: A Case Study on Island Tunneling Project of Hong Kong-Zhuhai-Macao Bridge. Front. Eng. Manag. 2018, 5, 78-87. [CrossRef]

47. Tam, C.M. Use of the Internet to Enhance Construction Communication:Total Information Transfer System. Int. J. Proj. Manag. 1999, 17, 107-111. [CrossRef]

48. Weippert, A.; Kajewski, S.L.; Tilley, P.A. Internet-Based Information and Communication Systems on Remote Construction Projects-A Case Study Analysis. Constr. Innov. 2002, 2, 103-116.

49. Zhang, L.; Liu, H.; Wang, G. Social Relation Cognitive Model on Virtual Prototyping Technology in Construction Project. Int. J. Online Eng. 2013, 9, 98-102. [CrossRef]

50. Das, M.; Cheng, J.C.P.; Law, K.H. An Ontology-Based Web Service Framework for Construction Supply Chain Collaboration and Management. Eng. Constr. Arch. Manag. 2015, 22, 551-572. [CrossRef]

51. Ahmed, U.; Petri, I.; Rana, O.; Raza, I.; Hussain, S.A. Federating Cloud Systems for Collaborative Construction and Engineering. IEEE Access 2020, 8, 79908-79919. [CrossRef]

52. Mosaic Project Services Pty Ltd. Stakeholder Management Overview. Available online: https://www.stakeholdermapping.com/ about/ (accessed on 10 July 2021).

53. Darzin Software. Darzin Software: Get a Stakeholder CRM. And Lose the Spreadsheet Chaos. Available online: https://www.darzin com/ (accessed on 10 July 2021).

54. Darzin Software. Stakeholder Engagement Teams: One CRM for All Your Engagement Activities. Available online: https: / / www.darzin.com/tour/whats-your-role/stakeholder-engagement/ (accessed on 10 July 2021).

55. Darzin Software. Consultation Management for the Mega Metro Tunnel. Available online: https://www.darzin.com/casestudies /mmra-metro-tunnel-consultation-management/ (accessed on 10 July 2021).

56. Arayici, Y.; Egbu, C.O.; Coates, S. Building Information Modelling (Bim) Implementation and Remote Construction Projects: Issues, Challenges, and Critiques. J. Inf. Technol. Constr. 2012, 17, 75-92.

57. Vilventhan, A.; Razin, S.; Rajadurai, R. 4D BIM Models for Smart Utility Relocation Management in Urban Infrastructure Projects. Facilities 2021, 39, 50-63. [CrossRef]

58. Maskil-Leitan, R.; Reychav, I. A Sustainable Sociocultural Combination of Building Information Modeling with Integrated Project Delivery in a Social Network Perspective. Clean Technol. Environ. Policy 2018, 20, 1017-1032. [CrossRef]

59. Liu, Y.; van Nederveen, S.; Hertogh, M. Understanding Effects of BIM on Collaborative Design and Construction An Empirical Study in China. Int. J. Proj. Manag. 2017, 35, 686-698. [CrossRef]

60. Badi, S.; Diamantidou, D. A Social Network Perspective of Building Information Modelling in Greek Construction Projects. Archit. Eng. Des. Manag. 2017, 13, 406-422. [CrossRef]

61. Kapogiannis, G.; Sherratt, F. Impact of Integrated Collaborative Technologies to Form a Collaborative Culture in Construction Projects. Built Environ. Proj. Asset Manag. 2018, 8, 24-38. [CrossRef]

62. Mutis, I.; Ramachandran, A. The Bimbot: Mediating Technology for Enacting Coordination in Teamwork Collaboration. J. Inf. Technol. Constr. 2021, 26, 144-158. [CrossRef]

63. Lin, Y.C.; Jung, S.; Su, Y.C. Construction Database-Supported and BIM-Based Interface Communication and Management: A Pilot Project. Adv. Civ. Eng. 2019, 2019, 8367131. [CrossRef]

64. Tallgren, M.V.; Roupé, M.; Johansson, M.; Bosch-Sijtsema, P. Bim-Tool Development Enhancing Collaborative Scheduling for Pre-Construction. J. Inf. Technol. Constr. 2020, 25, 374-397. [CrossRef]

65. Park, J.; Cai, H.; Dunston, P.S.; Ghasemkhani, H. Database-Supported and Web-Based Visualization for Daily 4D BIM. J. Constr. Eng. Manag. 2017, 143, 04017078. [CrossRef]

66. Abedi, M.; Fathi, M.S.; Mirasa, A.K.; Rawai, N.M. Integrated Collaborative Tools for Precast Supply Chain Management. Sci. Iran. A 2016, 23, 429-448. [CrossRef]

67. Zhang, J.; Liu, Q.; Hu, Z.; Lin, J.; Yu, F. A Multi-Server Information-Sharing Environment for Cross-Party Collaboration on a Private Cloud. Autom. Constr. 2017, 81, 180-195. [CrossRef]

68. Liston, K.; Fischer, M.; Winograd, T. Focused Sharing of Information for Multi-Disciplinary Decision Making by Project Teams. Electron. J. Inf. Technol. Constr. 2001, 6, 69-82.

69. Wen, J.; Gheisari, M. Using Virtual Reality to Facilitate Communication in the AEC Domain: A Systematic Review. Constr. Innov. 2020, 20, 509-542. [CrossRef]

70. Balali, V.; Zalavadia, A.; Heydarian, A. Real-Time Interaction and Cost Estimating within Immersive Virtual Environments. J. Constr. Eng. Manag. 2020, 146, 04019098. [CrossRef]

71. Zaker, R.; Coloma, E. Virtual Reality-Integrated Workflow in BIM-Enabled Projects Collaboration and Design Review: A Case Study. Vis. Eng. 2018, 6, 4. [CrossRef] 
72. Anderson, A.; Dossick, C.S.; Iorio, J.; Taylor, J.E. The Impact of Avatars, Social Norms and Copresence on the Collaboration Effectiveness of AEC Virtual Teams. J. Inf. Technol. Constr. 2017, 22, 287-304.

73. Chalhoub, J.; Ayer, S.K. Using Mixed Reality for Electrical Construction Design Communication. Autom. Constr. 2018, 86, 1-10. [CrossRef]

74. Dinis, F.M.; Sanhudo, L.; Martins, J.P.; Ramos, N.M.M. Improving Project Communication in the Architecture, Engineering and Construction Industry: Coupling Virtual Reality and Laser Scanning. J. Build. Eng. Improv. 2020, 30, 101287. [CrossRef]

75. Ventura, S.M.; Castronovo, F.; Ciribini, A.L.C. A Design Review Session Protocol for the Implementation of Immersive Virtual Reality in Usability-Focused Analysis. J. Inf. Technol. Constr. 2020, 25, 233-253. [CrossRef]

76. Abbas, A.; Choi, M.; Seo, J.; Cha, S.H.; Li, H. Effectiveness of Immersive Virtual Reality-Based Communication for Construction Projects. KSCE J. Civ. Eng. 2019, 23, 4972-4983. [CrossRef]

77. Al-Shehan, A.O.; Assbeihat, J.M. An Investigation of the Impact of Social Media on Construction Project Management. Civ. Eng. J. 2021, 7, 153-164. [CrossRef]

78. Lobo, S.; Abid, A.F. The Role of Social Media in Intrastakeholder Strategies to Influence Decision Making in a UK Infrastructure Megaproject: Crossrail 2. Proj. Manag. J. 2020, 51, 96-119. [CrossRef]

79. Nik-Bakht, M.; El-Diraby, T.E. Beyond Chatter: Profiling Community Discussion Networks in Urban Infrastructure Projects. J. Infrastruct. Syst. 2019, 26, 05020006. [CrossRef]

80. Minooei, F.; Sobin, N.; Goodrum, P.M.; Molenaar, K.R. Managing Public Communication Strategies in Accelerated Highway Construction Projects. Transp. Res. Rec. 2018, 26, 1-10. [CrossRef]

81. Nik-Bakht, M.; El-Diraby, T.E. Sus-Tweet-Ability: Exposing Public Community's Perspective on Sustainability of Urban Infrastructure through Online Social Media. Int. J. Hum. Comput. Stud. 2015, 89, 54-72. [CrossRef]

82. Nik-Bakht, M.; El-Diraby, T.E. Communities of Interest-Interest of Communities: Social and Semantic Analysis of Communities in Infrastructure Discussion Networks. Comput. Civ. Infrastruct. Eng. 2016, 31, 34-49. [CrossRef]

83. Ojelabi, R.; Oyeyipo, O.; Afolabi, A.; Amusan, L. Presence of Social Client Relationship Management within the Nigerian Construction Industry. Buildings 2018, 8, 60. [CrossRef]

84. Williams, N.L.; Ferdinand, N.; Pasian, B. Online Stakeholder Interactions in the Early Stage of a Megaproject. Proj. Manag. J. 2016, 46, 92-110. [CrossRef]

85. Yang, R.J. An Investigation of Stakeholder Analysis in Urban Development Projects: Empirical or Rationalistic Perspectives. Int. J. Proj. Manag. 2014, 32, 838-849. [CrossRef]

86. Trach, R.; Bushuyev, S. Analysis of Communication Network of the Construction Project Participants. Sci. Rev. Eng. Environ. Sci. 2020, 29, 388-396. [CrossRef]

87. Doloi, H. Assessing Stakeholders' Influence on Social Performance of Infrastructure Projects. Facilities 2012, 30, 531-550. [CrossRef]

88. Mok, K.Y.; Shen, G.Q.; Yang, R.J. Addressing Stakeholder Complexity and Major Pitfalls in Large Cultural Building Projects. Int. J. Proj. Manag. 2017, 35, 463-478. [CrossRef]

89. Almahmoud, E.; Doloi, H. Assessment of Social Sustainability in Construction Projects Using Social Network Analysis. Facilities 2015, 33, 152-176. [CrossRef]

90. Yang, R.J.; Zou, P.X.W. Stakeholder-Associated Risks and Their Interactions in Complex Green Building Projects: A Social Network Model. Build. Environ. 2014, 73, 208-222. [CrossRef]

91. Jafari, P.; Mohamed, E.; Lee, S.H.; Abourizk, S. Social Network Analysis of Change Management Processes for Communication Assessment. Autom. Constr. 2020, 118, 103292. [CrossRef]

92. Nik-Bakht, M.; El-Diraby, T.E. Project Collective Mind: Unlocking Project Discussion Networks. Autom. Constr. 2017, 84, 50-69. [CrossRef]

93. Lin, X.; Ho, C.M.F.; Shen, G.Q.P. Who Should Take the Responsibility? Stakeholders' Power over Social Responsibility Issues in Construction Projects. J. Clean. Prod. 2017, 154, 318-329. [CrossRef]

94. Doloi, H. Community-Centric Model for Evaluating Social Value in Projects. J. Constr. Eng. Manag. 2018, 144, 04018019. [CrossRef]

95. Trach, R.; Lendo-Siwicka, M. Centrality of a Communication Network of Construction Project Participants and Implications for Improved Project Communication. Civ. Eng. Environ. Syst. 2021, 38, 145-160. [CrossRef]

96. Yu, T.; Shen, G.Q.; Shi, Q.; Lai, X.; Li, C.Z.; Xu, K. Managing Social Risks at the Housing Demolition Stage of Urban Redevelopment Projects: A Stakeholder-Oriented Study Using Social Network Analysis. Int. J. Proj. Manag. 2017, 35, 925-941. [CrossRef]

97. Bourne, L.; Walker, D.H.T. Using A Visualising Tool to Study Stakeholder Influence-Two Australian Examples. Proj. Manag. J. 2006, 37, 5-21. [CrossRef]

98. Zhang, Y.; Hu, H.; Xu, F. Social Network Visual Simulation for Process Reengineering of Construction Change Management under Building Information Modelling Technology. J. Intell. Fuzzy Syst. 2020, 39, 1471-1480. [CrossRef]

99. Godager, B.; Onstein, E.; Huang, L. The Concept of Enterprise BIM: Current Research Practice and Future Trends. IEEE Access 2021, 20, 42265-42290. [CrossRef]

100. Shrahily, R.; Medjdoub, B.; Klalib, H.; Chalal, M.; Alwetaishi, M. Managing Construction Site Communication Using the Responsibility Assignment Matrix (RAM) System. Int. J. Constr. Manag. 2020, 1-21. [CrossRef]

101. Heydarian, A.; Carneiro, J.P.; Gerber, D.; Becerik-Gerber, B.; Hayes, T.; Wood, W. Immersive Virtual Environments versus Physical Built Environments: A Benchmarking Study for Building Design and User-Built Environment Explorations. Autom. Constr. 2015, 54, 116-126. [CrossRef] 